\title{
A Randomized Clinical Trial of Misoprostol and Oxytocin for Induction of Labour
}

\author{
Loto OM', Ayuba II', Adebara IO', Ikuomola AA', Onwudiegwu U'. \\ Dept of Obs /Gyn', Obafemi Awolowo University Teaching Hospitals Complex,lle-lfe. Nigeria. \\ Dept of Obs /Gyn², University of Ilorin Teaching Hospital, Ilorin. Nigeria.
}

\begin{abstract}
Aim: To compare the outcome of induction of labour with vaginal misoprostol and oxytocin titration.

Method: Women who have unequivocal indications for induction of labour and met the inclusion criteria were randomized into two groups: vaginal misoprostol tablets 50ug repeated 4hourly until adequate uterine contractions of 3 in 10 minutes or a maximum total daily dose of $200 \mathrm{ug}$ of misoprostol is reached. The second group had synchronous use of oxytocin titration after forewater amniotomy. All patients with Bishop score less than seven in the two groups had cervical ripening with insertion of intracervical Foley catheter for uniformity in cervical score. The outcome of labour was compared in the two groups.
\end{abstract}

Results: The mean induction - delivery interval and duration of labour in hours is 12.62 and 12.67 hours respectively in the study group which is slightly lower than the control but was not statistically significant $P>0.05$. The mean Apgar scores at 1 and 5 minutes were 8.72 and 9.12 respectively which were not statistically different in both the control and the study. 6 patients had caesarean section for failed induction in the misoprostol arm (8.8\%) which is not statistically different from the Caesarean Section rate of $10.2 \%$ in the control. There was only one case of uterine hyper stimulation in the misoprostol group and none in the oxytocin arm.

Conclusion: The outcome of induction of labour with misoprostol is comparable to the use of oxytocin titration.

Keywords: Misoprostol, Oxytocin, labour induction.

\section{Introduction}

Induction of labour is a common intervention during pregnancy in both the developed and developing countries $^{1,2}$. It is indicated in medical, obstetric and fetal conditions in which prolongation of the pregnancy would jeopardize fetal or maternal wellbeing and in which there are no contraindications to vaginal delivery and the use of amniotomy, oxytocin and prostaglandin.

Induction of labour can be achieved by surgical or medical methods or by a combination of both. A popular method of labour induction in term pregnancies is fore-water amniotomy and synchronous oxytocin infusion ${ }^{3}$. This has been employed for more than fifty years ${ }^{4}$. Although prostaglandins are widely used for this purpose along with oxytocin in developed countries, oxytocin alone remains the major drug for medical induction in the developing nations ${ }^{5}$.

Misoprostol [Cytotec, Searle] is a synthetic prostaglandin E1 analogue, which was developed for prevention and treatment of peptic ulcer ${ }^{6}{ }^{7}$. Misoprostol is a promising agent in cervical ripening, induction of labour, and the management of third stage of labour. Compared with other prostaglandins, it is easily stored and transported at room temperature, inexpensive with effective uterotonic action. It is easily absorbed orally, vaginally, rectally and sublingually. It may therefore be a veritable alternative for induction of labour in developing countries, due to challenges in maintaining the potency of oxytocin as a result of

Correspondence

Dr. Olabisi M Loto MB. ChB, FWACS, FMCOG (Nig)

Senior Lecturer /Consultant, Dept of Obs /Gyn and Perinatology

Obafemi Awolowo University/University Teaching Hospital

Ile-Ife Osun State, Nigeria.

Mob. : +2348066546725

E-mail: bisiloto@yahoo.co.uk,lotobisi@oauife.edu.ng 
storage conditions. This study therefore compares the outcome of labour induction with misoprostol and oxytocin in a tertiary hospital in Nigeria.

\section{Methods}

This prospective randomized clinical trial was carried out at the Obstetrics and Gynaecological Department of the Obafemi Awolowo University Teaching Hospitals Complex, Ile-Ife, Osun State, Nigeria, comprising two obstetric units of Ife Hospital Unit (IHU) and Wesley Guild Hospital (WGH), Ilesha between January $1^{\text {st }}$ and July $31^{\text {st }} 2009$.

These hospitals serve as tertiary referral centres for secondary and primary tiers of hospitals in Ife-Ijesha, Ondo and Ekiti Zones of the country. The two obstetric units conduct an average of 2,150 deliveries every year with an induction rate of $15.7 \%$.

Pregnant women of low parity, at term with singleton fetuses in cephalic presentation admitted for induction of labour were counseled and after consenting were randomized to participate in the study. Induction of labour was commenced for those whose Bishop's Score is at least 7. Those with lower Bishop's score in both groups had ripening with Foley catheter before being recruited into the study.

Using appropriate sample size calculation, which gave a minimum of 60 subject per arm of the study, 132 women who met the inclusion criteria and consented to the study were randomly assigned to assigned to 30 minutes oxytocin infusion incremental interval which will serve as the control group and vaginal misoprostol 50ug four-hourly which is the experimental group. The study was approved by the institution ethical committee.

The 30-minutes oxytocin group had induction of labour with oxytocin base mixture of 5iu of oxytocin in 500mls of Ringer's lactate and oxytocin infusion was administered via primed intravenous giving set with size $20 \mathrm{G}$ cannula using gravity fed counting drops technique. The starting dose was $5 \mathrm{mu} / \mathrm{min}(10$ drops) and increased every 30 minutes until adequate uterine contractions (defined as 3 contractions within 10 minutes each lasting 40-60 seconds) are achieved or to a maximum of $32 \mathrm{mu} / \mathrm{min}$ ( 64 drops per minute).

The misoprostol group had induction of labour with $50 \mathrm{ug}$ misoprostol tablet placed in the posterior vaginal fornix and dose repeated every 4 hours till adequate uterine contractions of 3 in 10 minutes or total maximum dose of 200ug which was the average dose required for delivery in most studies is reached. The $50 \mathrm{ug}$ was obtained by splitting a scored $200 \mathrm{ug}$ tablets into 4 equal parts. The patients were advised to empty their bladders just before each administration and were also advised to remain in bed for the next 30 minutes following insertion of the misoprostol.

Labour was monitored partographically in both groups to detect any abnormality in the progress of labour. The Pinnard stethoscope was used to monitor fetal heart tone every 15 minutes throughout labour.

Information obtained at the end of this study was processed using the computer Software Package for Social Science (SPSS) version 10. Frequency tables were generated and results tested for significance using the student t-test for continuous variables and chi square for categorical variables with level of significance (x) set at 0.05 .

\section{Results}

140 patients met the inclusion criteria into the study. However, 4 patients originally randomized to the 2 arms of the study (2 in each group) started having contractions and thus were excluded.

Table 1 shows the demographic characteristics of the parturient including mean age, mean parity, mean bishop score, mean gestational age in weeks and mean birth weight. There were no statistically significant

\section{Table 1.Demographic characteristics of the parturient}

\begin{tabular}{llll}
\hline Variable & Study & Control & P-value (NS) \\
\hline Age & $30.34 \pm 4.41$ & $30.22 \pm 5.63$ & 0.147 \\
Parity & $2.03 \pm 0.81$ & $2.18 \pm .88$ & 0.099 \\
Gestational age & $38.90 \pm 1.50$ & $39.03 \pm 1.50$ & 0.924 \\
Bishop score & $8.91 \pm 1.03$ & $8.29 \pm 0.99$ & 0.414 \\
Birth weight $(\mathrm{kg})$ & $3.13 \pm 0.46$ & $3.18 \pm 0.40$ & 0.113 \\
\hline
\end{tabular}

Data are presented as mean $+_{/-S D}$ 
Table 2. Indications for induction of labour among cases and control

\begin{tabular}{lcccc}
\hline \multicolumn{1}{c}{ Indications } & Study & \multicolumn{2}{c}{ Control } \\
& Frequency & Percent & Frequency & Percent \\
\hline Post term pregnancy & 42 & 61.8 & 38 & 55.9 \\
PROM & 20 & 29.4 & 26 & 38.2 \\
IUFD & 3 & 4.4 & 2 & 2.9 \\
Congenital Anomaly & 3 & 4.4 & 2 & 2.9 \\
\hline Total & $\mathbf{6 8}$ & $\mathbf{1 0 0 . 0}$ & $\mathbf{6 8}$ & $\mathbf{1 0 0 . 0}$ \\
\hline
\end{tabular}

Table 3. Events in labour of the parturient

\begin{tabular}{llll}
\hline Variable & Study & control & P-value \\
\hline Dose of Misoprostol $\mu \mathrm{g}$ & $98.53 \pm 17.21$ & $0.0 \pm 0.0$ & $0.000 \mathrm{~S}$ \\
Duration of labour in hours & $12.67 \pm 3.28$ & $13.37 \pm 2.78$ & $0.354 \mathrm{NS}$ \\
Induction delivery interval in hrs & $12.62 \pm 3.28$ & $13.32 \pm 2.78$ & $0.350 \mathrm{NS}$ \\
Apgar score at 1 minute & $8.72 \pm 2.47$ & $8.93 \pm 2.49$ & $0.907 \mathrm{NS}$ \\
Apgar score at 5 minutes & $9.12 \pm 2.43$ & $9.09 \pm 2.44$ & $0.940 \mathrm{NS}$ \\
Estimated blood loss (ml) & $302.35 \pm 97.27$ & $296.69 \pm 70.41$ & $0.100 \mathrm{NS}$ \\
\hline
\end{tabular}

Table 4. Induction delivery time interval and duration of labour between Study and Control

\begin{tabular}{|c|c|c|c|c|c|c|c|c|}
\hline \multirow[b]{3}{*}{ Period } & \multicolumn{4}{|c|}{ Induction delivery time interval } & \multicolumn{4}{|c|}{ Duration of Labour } \\
\hline & \multicolumn{2}{|c|}{ Study } & \multicolumn{2}{|c|}{ Control } & \multicolumn{2}{|c|}{ Study } & \multicolumn{2}{|c|}{ Control } \\
\hline & Freq & $\%$ & Freq & $\%$ & Freq & $\%$ & Freq & $\%$ \\
\hline$<6 \mathrm{hrs}$ & - & - & 4 & 5.9 & - & - & 4 & 5.9 \\
\hline $6-10 \mathrm{hrs}$ & 6 & 8.8 & 6 & 8.8 & 5 & 7.4 & 5 & 7.4 \\
\hline$>10 \mathrm{hrs}$ & 62 & 91.2 & 58 & 85.3 & 63 & 92.6 & 59 & 86.8 \\
\hline Total & 68 & 100.0 & 68 & 100.0 & 68 & 100.0 & 68 & 100.0 \\
\hline$X^{2}$ & & & 4.133 & & 4.131 & & & \\
\hline Df & & & 2 & & & & 2 & \\
\hline P-value & & & 0.127 & & & & 0.127 & \\
\hline
\end{tabular}

differences in any of these 5 variables; indicating that baseline characteristics of patients remained similar in the 2 arms of the study. Table 2 shows the indications for induction of labour in the subjects.
The total misoprostol dose required to induce labour ranged from 50ug (single insertion) in 5 patients $(7.32 \%)$, to 150 ug ( 3 insertions) in 3 patients $(4.41 \%)$. The mean dose of misoprostol required was $98.53 \mathrm{ug}$ 
as shown in Table 3. Table 3 also shows that the mean induction - delivery interval and duration of labour in hours is 12.62 and 12.67 hours respectively in the study and the control group. This was not statistically significant $(\mathrm{P}>0.05)$.

The mean Apgar scores at 1 and 5 minutes were 8.72 and 9.12 respectively which were not statistically different in both the control and the study. The induction delivery interval is as shown on table 3 . The induction delivery time interval for cases and controls is as shown on Table 4.

6 patients had caesarean section for failed induction in the misoprostol arm $(8.8 \%)$ which is not statistically different from the Caesarean Section rate of $10.2 \%$ in the control. There was only one case of uterine hyper stimulation in the misoprostol group and none in the oxytocin arm.

All the 5 still births recorded in this study were in patients induced on account of intrauterine foetal death -3 in the study group and 2 in the control group.

\section{Discussion}

The mean age from this study is 30.34 years, mean parity of 2.14 , mean gestational age of 38.9 weeks. These findings were similar to a study from Turkey which has mean maternal age of 28.9 yrs, parity 2.5 and mean gestational age of 38.4 weeks respectively. However, the mean Bishop score of 8.9 from this study is different from the mean of 3.2 from the Turkish study $^{7}$. This difference was due to the fact that over $88 \%$ of the patients in both groups had Bishops scores of over $7 / 13$ at presentation, and the remainder had cervical ripening with Foley catheter. This is to ensure uniformity in cervical score for objective comparison of the methods used.

Misoprostol is absorbed rapidly when administered orally, vaginally, rectally or sublingually. The vaginal route is advantageous because peak levels are reached slowly and sustained for long and this is associated with fewer gastrointestinal side effects. The mean dose of vaginal misoprostol required in this study to effect delivery was $98.53 \mathrm{ug}$. The relationship between Bishop Score and total dose of misoprostol was highlighted by the Turkish study ${ }^{7}$, with a mean dose of $120.5 \mathrm{ug}$ required to effect delivery.

Systematic use of the Bishop score could allow better adjustment of misoprostol doses and perhaps encourage intracervical administration of misoprostol. Furthermore, majority of the patients ( $88 \%$ ) had just 2 insertions and only $3(4.4 \%)$ patient had 3 insertions. This is probably due to the high Bishop score at the time of insertion.
The mean induction delivery interval and duration of labour were 12.62 and 12.67 hours respectively in the study group. Which is slightly lower than control group; though not statistically significant? This is comparable with $11.5 \mathrm{hrs}, 15.01 \mathrm{hrs}$ and $12.4 \mathrm{hrs}$ from previous studies by Sanchez-Ramos et $\mathrm{al}^{8}$, Wing et al, ${ }^{9}$ and Nakintu ${ }^{10}$ respectively; and is much lower than 20.6 hrs reported by Pajak et al $^{6}$. The majority of the women $(91.2 \%)$ in this study delivered within 16hours. This could be considered an advantage to them and their families. It also reduced the congestion in labour ward and Lying in-ward. All the patients were delivered within 24 hours of inserting the first dose of misoprostol tablets.

15 patients $(22 \%)$ had augmentation with oxytocin; which was lower than $45.7 \%$ in the Turkish study ${ }^{7}$. This could also be explained by the higher Bishop score in this study.

6 patients $(8.8 \%)$ had Caesarean Section for failed induction in the study group which was not statistically different from the $7(10.2 \%)$ that had Caesarean Section in the control group. This is slightly lower than the rate of $11.4 \%$ and $13.3 \%$ reported in similar studies by Sanchez-Ramos et al, and Wing et al respectively ${ }^{8,9}$. The higher Caesarean Section rate among the oxytocin arm of these previous studies may be related to the limited effect of oxytocin on the cervix. Its unfavourability placed the oxytocin arm at a disadvantage, because while misoprostol acts at both the cervical level and uterine level; oxytocin effect is principally on the uterus.

This was further confirmed in this study in which there was no statistically significant difference in the rate between the two arms of the study due to the similar favourable baseline cervical score.

A concern among the misoprostol treated patients is the occurrence of hyperstimulation ${ }^{8,10-13}$. There was one case $(1.4 \%)$ of uterine hyperstimulation in this study with none in the control, which is not statistically significant. However, this rate is much lower than $8.6 \%$ reported by Sanchez-Ramos et $\mathrm{al}^{8}$ and $3 \%$ by Loto et $\mathrm{al}^{14}$ this may be due to the lower dose of misoprostol used in our study and different demographic variables in the patient population.

Analysis of the other undesirable side effects are uncommon as shown in this study which is in tandem with a previous study by Mundle and Young ${ }^{15}$. These undesirable side effects were however found to be self-limiting and shivering responded to simple cover with blankets.

Neonatal Intensive Care unit admission rate varies between $8.7 \%$ and $25.5 \%$ in the literature ${ }^{10,12,16}$. 
Abnormal foetal heart tracing and me conium stained liquor were reported in $29.6 \%$ and $8.1 \%$ respectively 9,12 .

The mean first and fifth minute Apgar scores were 8.7and 9.12 in the study group which was comparable with the control. This is comparable with the mean fifth minute Apgar score of 8.8 from the Turkish study ${ }^{7}$. None of the babies was admitted into the neonatal intensive care unit in this study, compared with $7 \%$ in the study by Sanchez-Ramos et $\mathrm{al}^{8}$. The difference may be due to varying neonatal intensive care unit admission criteria.

In conclusion, this study has shown that labour induction with misoprostol is as safe and effective as induction with oxytocin titration; in addition the Caesarean Section rate, induction-delivery interval and other maternal and neonatal variables are not statistically different from induction of labour with oxytocin titration.

Misoprostol is cheap compared with oxytocin, has long shelf life, is thermo-stable, hence no need for refrigeration or special training before it can be administered.

The use of misoprostol is relevant in our environment where lack of facilities for storage of oxytocin, its higher cost and adulterated forms are a daily reality. This being so, misoprostol must certainly be restricted to well organized obstetrical units; under the surveillance of experienced obstetricians and certainly also used within a well- defined protocol.

Finally, while the use of misoprostol is an undeniable progress in the management of labour, dosage is a key issue that remains unresolved both practically and theoretically. The benefits of lower dose of misoprostol (i.e 25-50ug), particularly in relation to reduce rates of uterine hyperstimulation has become clear. The route of delivery and delivering of that dose remains an issue as only 200ug tablets are available in our environment and splitting tablets is not a precise method of delivering lower doses. Hence, the need for further studies to resolve these key issues.

\section{References}

1. Kwawukume EY. Induction and Augmentation of labour. In: Kwawukume EY, Emuveyan EE (eds). Comprehensive Obstetrics In The Tropics. Ghana, Asante \&Hittscher Accra, 2002; 129. 134.

2. Hofmeyr GJ, Alfirevic Z, Matonhodze B, Brocklehurst P, Cambell E, Nikodem VC. Titrated oral misoprostol solution for induction of Labour: a multi-centre, randomized trial. British
J ObstetGynaecol 2001; 108: 952 - 959.

3. Orhue AAE. A randomized trial of 30-min and 15-min oxytocin infusion regimen for induction of labour at term in women of low parity.Int $\mathrm{J}$ GynaecolObstet 1993; 40: 219-225.

4 Dujandin B , Boutsen M, De Schampheleire I, Kulker R. Oxytocics in developing countries. Int J GynaecolObstet 1995; 50: 243 - 251.

5. Zeeman GG, Khan-Dawood FS, Dawood MY. Oxytocin and its receptor in pregnancy and parturition: Current concept and clinical implications. J ObstetGynaecol 1997; 89(5): 873 $-883$.

6. Allan T. Misoprostol for All? British Journal of Obstetrics and Gynaecology, 1998; 105 : 937939

7. Ozan II, Uncu G, Yildirim V, Omak M, Kara IIF and Tfekci M. Misoprostol in labour induction: J. ObstetGynaecol. 2001: 27(1): 17-20.

8. Sanchez-Ramso L, kaunitzAM, Weass RL, Delke I, Gaudier FL. Misoprostol for cervical ripening and labour induction: A meta-analysis. Obstet. Gynecol 1997; 89: 633-42.

9. Wing DA, Rahall A, Jones MM, Goodwin TM and Paul RH. Misoprostol: An effective agent for cervical ripening and labour induction: Am. J. ObstetGynaecol. 1995; 172(6): 1811-1816.

10. Nakintu NA. comparative study of vaginal misoprostol and intravenous oxytocin for induction of labour in women with intra uterine fetal death in Mulago Hospital, Uganda; African Health Sciences 1(2): 55-59.

11. Hofmeyr GJ. Induction of labour with misoprostol: Current opinion in Obstetrics and Gynaecology: 2001; 13: 577-581.

12. Wing DA, Tran S, Paul RH. Factors affecting the likelihood of successful induction after intravaginal misoprostol application for cervical ripening and labour induction. Am J ObstetGynaecol 2002; 186(6): 1237-40.

13. American college of Obstetrician and Gynaecologists ACOG Committee Opinion: induction of labour with misoprostol ACOG. Practice Bulletin. Washington D.C 1999.

14. Loto OM, Fadahunsi AA, Kolade CO. Safety and efficacy of misoprostol for induction of labour in a semi-urban hospital setting. J ObstetGynaecol 2004; 24(6):638-640.

15. Mundle W.R and Young D.C. vaginal Misoprostol for induction of labour: A randomized controlled trial. Am J. Obstet. Gynecol. 1996: 88(4): 5215.

16. Pajak, J, Tomialowicz M, Florjanski J. Comparsion of vaginal misoprostol and oxytocin for labour induction in post - term pregnancy: Ginekol Pol 2001; 72(12A): 1300-4. 